Case Report

\title{
Congenital laryngeal stridor-a double trouble
}

\author{
Sivaranjini Venkatesan, Vikram Raj Mohanam T.C.*, Mary Kurien, Lalitha Krishnan
}

Department of ENT, Pondicherry Institute of Medical Sciences, Puducherry, India

Received: 28 December 2021

Revised: 04 February 2022

Accepted: 07 February 2022

\section{*Correspondence:}

Dr. Vikram Raj Mohanam T.C.,

E-mail: drtcvikram@gmail.com

Copyright: (C) the author(s), publisher and licensee Medip Academy. This is an open-access article distributed under the terms of the Creative Commons Attribution Non-Commercial License, which permits unrestricted non-commercial use, distribution, and reproduction in any medium, provided the original work is properly cited.

\begin{abstract}
Hemangiomas of the airway are benign vascular lesions that can involve any site from the nares to the tracheobronchial tree. It is the most common head and neck tumors in infants. Most of these lesions are seen in the subglottic area in infants. The presence of supraglottic hemangioma is rarely described. This may be due to less likely chance of symptoms and the tendency of infantile hemangiomas to involute without therapy over time. Also, the occurrence of supraglottic hemangioma as a synchronous airway lesion (SAL) with laryngomalacia (LM) is very rare, with most common lesions being tracheal bronchus, tracheomalacia, bronchomalacia and subglottic stenosis We report a rare case of supraglottic hemangioma involving laryngeal surface of epiglottis, as an uncommon SAL with LM, both being unveiled during the evaluation for stridor in a sixty-five-day old infant. It responded well to medical treatment with oral propranolol as it is for most infantile hemangiomas.
\end{abstract}

Keywords: Epiglottis, LM, Supraglottic hemangioma, SAL, Propranolol

\section{INTRODUCTION}

Laryngomalacia (LM) is the most common cause of congenital stridor in infants, accounting for approximately $60 \%$ of all congenital laryngeal anomalies typically presenting at 4-6 weeks of age. ${ }^{1}$ Most common classification for anatomic variations of supraglottic structural collapse in LM was described by Olney et al as type 1- prolapse of mucosa overlying the arytenoid cartilages; type 2-foreshortened aryepiglottic folds and type 3-posterior displacement of the epiglottis (retroflexed). ${ }^{2}$ Associated SALs, like tracheal bronchus, tracheomalacia, bronchomalacia, subglottic stenosis or hemangioma occur in $19 \%$ to $27 \%$ of LM. ${ }^{3}$ Supraglottic hemangioma is very rare with only one described on middle and left part of epiglottis and left aryepiglottic fold. Supraglottic hemangioma as a SAL is also rare, with only 3 cases being reported, lately by Len et al in $2014 .^{4}$

\section{CASE REPORT}

Sixty-five-day old male baby was admitted with cough, rhinitis and noisy breathing for one week. The infant was delivered at $37^{\text {th }}$ week of gestation by emergency caesarean section for fetal distress. Apgar score was 9/10, and birth weight was $3220 \mathrm{gm}$. On $22^{\text {nd }}$ day, he was admitted in neonatal intensive care unit for failure to thrive. On admission, child was afebrile, vitals stable and had intermittent stridor occasionally at rest, being more prominent in supine position. He had mild leukocytosis with neutrophilic predominance and elevated CRP. Chest $\mathrm{X}$-ray showed bilateral hyperinflation with no steeple sign or cardiomegaly with normal ECHO. The infant was admitted in pediatric ICU with a provisional diagnosis of bronchiolitis. He was started on supplemental oxygen, salbutamol and 3\% saline nebulization initially and being refractory to it, changed to adrenaline and budesonide nebulization. In view of persistent stridor on day 2 following admission, ENT consultation with trans-nasal awake flexible nasopharyngolaryngoscopy using Olympus $2.2 \mathrm{~mm}$ flexible fiberoptic laryngoscope revealed a curled-up, overhanging epiglottis that collapsed posteriorly along with arytenoid and aryepiglottic fold falling forwards on inspiration, obstructing the laryngeal inlet. Thus, confirming the infant had type 3 LM. However, in addition, a smooth 
surfaced submucosal reddish bulge suggestive of hemangioma was noted on the laryngeal surface of epiglottis (Figure 1). Both vocal cords were normal and mobile with adequate airway at glottic level (Figure 1). This was further confirmed by a careful review of laryngoscopic recordings.

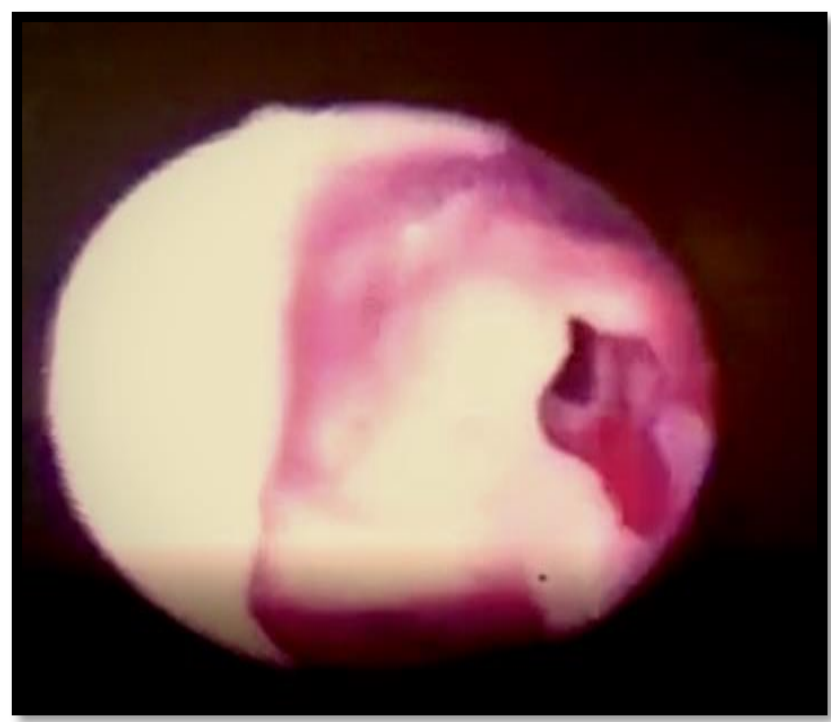

Figure 1: Endoscopy revealing hemangioma on laryngeal surface of epiglottis.

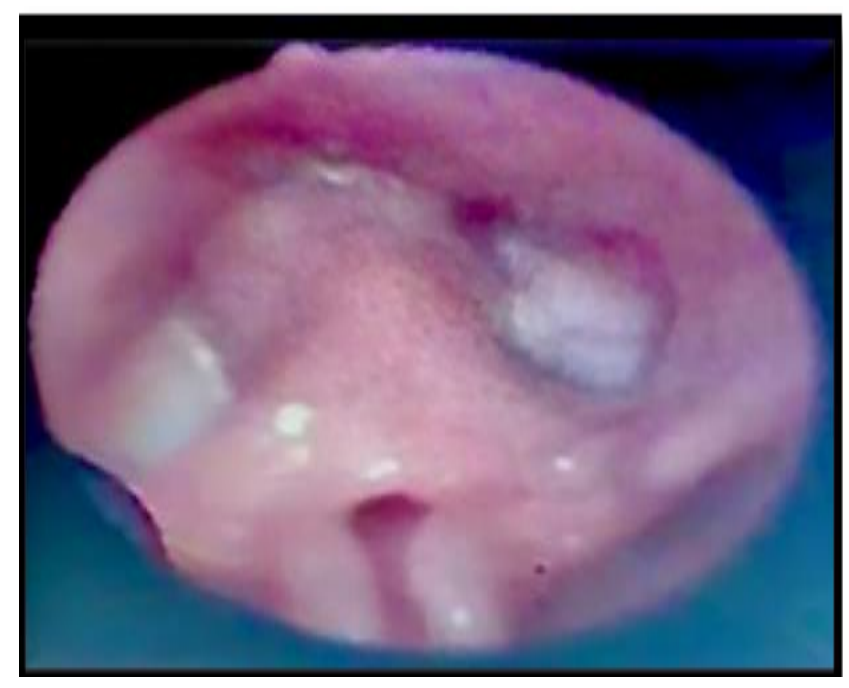

Figure 2: Endoscopy revealing regressed hemangioma after seven months of oral propranolol.

A clinical diagnosis of LM (type 3) with supraglottic hemangioma was made. Considering the classical proliferative stage of hemangioma being the first few weeks to months of infancy, conservative management of LM with a trial of oral propranolol was decided in this very young infant by pediatrician following due discussion. Cardiac and pulmonary status on evaluation was normal. He was then started on oral propranolol of 1 $\mathrm{mg} / \mathrm{kg} /$ day in 3 divided doses, with feeding in prone position under continuous pulse and blood pressure monitoring. Stridor reduced on day 3 and blood pressure was normal throughout the duration of hospital stay of 7 days, being discharged when he started feeding well. The infant continued to feed well and gained weight adequately on regular follow up by the pediatrician with no recurrence of stridor. Repeat nasopharyngolaryngoscopy done at 9 months of age revealed almost $90 \%$ regression of the hemangioma with only a mild reddish hue on the laryngeal surface of epiglottis (Figure 2). Following this, oral propranolol was discontinued, duration of medication being seven months. Recent telephonic contact with his parents revealed that infant had a relatively uneventful year except for an episode of bronchopneumonia at one year of age, during which time he had no respiratory distress and was cured with antibiotics requiring two days of hospitalization. He is at present two years old with normal milestones.

\section{DISCUSSION}

Hemangiomas comprise about $1.6 \%$ of all congenital laryngeal anomalies, majority being in the subglottic area in infants. The presence of supraglottic hemangioma and its incidence as a SAL in infants with LM is rarely described.

Airway haemangiomas can occur de novo as only $50 \%$ of these patients have associated cutaneous haemangiomas. ${ }^{5}$ Infantile laryngeal hemangioma, like any cutaneous hemangioma traverses a clinical course of active growth (proliferation) and later tumor regression (involution).

Proliferation begins during the first few weeks of life which generally continues for 4-10 months, followed by a period of quiescence during which the growth rate of the lesion stabilizes, followed by involution at 12-18 months and can last up to 5-6 years. ${ }^{5}$ Early therapeutic intervention during the proliferative stage is important. In the past, interventions like steroids, chemotherapy agents (such as vincristine and alpha-interferon), laser treatment, surgical excision, tracheostomy, or a combination of these therapies have been used to reduce the chance of airway compromise. It is reported that mean age of the patients at decannulation was 17 months when tracheostomy alone was used to treat laryngeal haemangiomas. ${ }^{6}$

Dr. Christine Léaute-Labrèze reported the serendipitous discovery of propranolol in the treatment of infantile hemangioma and now, medical management with oral propranolol has evolved as its primary treatment of choice. ${ }^{7}$ Propranolol is a non-selective $\beta$-blocker and its proposed mechanisms of effect of on infantile hemangioma are vasoconstriction, decreased expression of vascular endothelial growth factor (VEGF) and triggering of apoptosis of capillary endothelial cells. ${ }^{8}$ Prior to treatment, ECHO, baseline pulse and blood pressure are to be recorded. Oral propranolol is generally started with a dose of $0.5-1 \mathrm{mg} / \mathrm{kg} / \mathrm{day}$. The peak effects of oral propranolol on heart rate and blood pressure occur one to three hours after administration, requiring patients' heart and blood pressure to be measured at baseline, 
repeated at one and two hours after receiving the initial dose of propranolol and again after every dose increase of $0.5 \mathrm{mg} / \mathrm{kg} /$ day as well. ${ }^{9}$

\section{CONCLUSION}

LM, the commonest cause of stridor in infants, necessitates urgent trans-nasal awake fiberoptic nasopharyngoscopy by the consulting otolaryngologists. Awareness and identification of possible co-existing SALs including hemangioma is of paramount importance for prompt medical management to overcome impending airway obstruction, thus avoiding unnecessary surgical procedures, as in this case.

Funding: No funding sources

Conflict of interest: None declared

Ethical approval: Not required

\section{REFERENCES}

1. Gerber ME, Chen Jl. Congenital Laryngeal Anomalies. In Charles D. Bluestone, Jeffrey P. Simons, Gerald B. Healy (Ed.). Bluestone and Stool's Pediatric Otolaryngology, $5^{\text {th }}$ Edition. USA Shelton, Connecticut: People's Medical Publishing House. 2014;1:1517-20.

2. Olney DR, Greinwald JH, Smith RJ, Bauman NM. Laryngomalacia and its treatment. Laryngoscope. 1999;109(11):1770-5.

3. Schroeder JW, Bhandarkar ND, Holinger LD. Synchronous Airway Lesions and Outcomes in Infants with Severe Laryngomalacia Requiring Supraglottoplasty. Arch Otolaryngol Head Neck
Surg. 2009;135(7):647-51

4. Len A, Yehudah R, Avigdor M, Dorit A, Tal M. Supraglottic Hemangioma in an Infant. Int J Pediatr Otorhinolaryngol Extra. 2014;9:10.

5. Elluru RG, Bromwich M, Cohen AP. Hemangiomas and Vascular Malformations. In Charles D. Bluestone, Jeffrey P. Simons, Gerald B. Healy (Ed.). Bluestone and Stool's Pediatric Otolaryngology, $5^{\text {th }}$ Edition. USA Shelton, Connecticut: People's Medical Publishing House. 2014;1:1906-8.

6. Sebastian B, Kleinsasser O. Treatment of laryngeal hemangiomas in children. Laryngol Rhinol Otol (Stuttg). 1984;63:403-7.

7. Léauté-Labrèze $\mathrm{C}$, De la Roque $\mathrm{ED}$, Hubiche $\mathrm{T}$, Boralevi F, Thambo JB, Taïeb A. Propranolol for severe hemangiomas of infancy. $\mathrm{N}$ Engl J Med. 2008;358:2649-51.

8. Melo JN, Rotter A, Rivitti-Machado MC, Oliveira ZN. Propranolol for treatment of infantile hemangiomas. An Bras Dermatol. 2013;88(6-1):2203 .

9. Shah MK, Vasani RJ. Use of propranolol in infantile hemangioma. Indian J Drugs Dermatol. 2017;3:4852 .

Cite this article as: Venkatesan S, Mohanam VRTC, Kurien M, Krishnan L. Congenital laryngeal stridor-a double trouble. Int J Otorhinolaryngol Head Neck Surg 2022;8:267-9. 